\title{
Risk Management in Moroccan Healthcare Organizations: An Overview
}

\author{
En-Naaoui $^{a^{*}}$, M. Kaicer ${ }^{\text {b }}$, J. El Harti ${ }^{\mathrm{c}}$, H. Hachimi ${ }^{\mathrm{d}}$, F. Khamlichi Idrissi ${ }^{\mathrm{e}}$, A. Darouichi ${ }^{\mathrm{f}}$, S.M. \\ Lamarti $^{\mathrm{g}}$
}

\author{
${ }^{a *}$ Informatics, Systems and Optimization Laboratory, Faculty of Sciences, Ibn Tofail University Kenitra- \\ Morocco. E-mail: naoui.amine.amine@gmail.com \\ ${ }^{b}$ Informatics, Systems and Optimization Laboratory, Faculty of Sciences, Ibn Tofail University Kenitra- \\ Morocco. \\ 'Laboratory of Medicinal Chemistry, Faculty of Medicine and Pharmacy, Mohamed V University Rabat- \\ Morocco. \\ ${ }^{\mathrm{d} S u l t a n}$ Moulay Sliman University Beni Mellal-Morocco. \\ ${ }^{\mathrm{e}}$ Devoteam Rabat Morocco. \\ Informatics engineering and Systems Laboratory, Cadi Ayyad University Marrakech-Morocco. \\ ${ }^{\mathrm{g}}$ Applied Sciences and Didactics Laboratory, Superior Normal School, Adelmalek Essaadi Tetouan-Morocco.
}

Article History: Received: 11 January 2021; Accepted: 27 February 2021; Published online: 5 April 2021

\begin{abstract}
The institute of medicine asserts that to err is human: building a safer health system (Linda $\mathrm{T}$ et al, 2000). For this reason risk management takes an important place in healthcare decision-making process within the objective of ensuring the management of emergencies, which cannot always be anticipated in advance, but will cause serious consequences if they occur (Li Guo, 2015). In fact, risk management is defined as a set of activities and processes of identification, analysis, evaluation, treatment, reducing, communication and monitoring potential failures and adverse events in purpose to provide a better quality of service and a system able to insure protection of patients, workers, equipment, stakeholders and the environment. Thus, this paper aims to present a structured review of publications that highlight risk management topic in healthcare sector by proposing new approaches, applying existed techniques or implementing risk assessment plans in Moroccan healthcare organizations especially Moroccan hospitals.
\end{abstract}

Keywords: Overview, Risk Management, Risk Assessment Technique, Healthcare Organization, Hospital.

\section{Introduction}

A healthcare organization is a complex organization by nature (A. Aggarwal et al, 2019). This complexity is generated by various reasons such as the diversity of activities and the multiple interactions and trade-offs between internal and external stakeholders. This interactivity generates several failure modes and adverse events which decrease the quality of care and the safety system in all processes of patient journey.

In fact, a healthcare organization is considered as a socio-technical context, which means the hospital system is faced to human errors and technical failure that may impact on patient safety and overall healthcare system (M. LI, 2019). For this reason, decision-makers should implement efficient risk management programs in order to correct errors and prevent potential unwanted events.

Consequently, in recent decades, several scientific and academic studies in the worldwide have been made in order to contribute in developing risk and implemanting risk assessment methods through adopting approaches and techniques from other sectors. Therefore, several methods have been adopted from the industrial context before they have been applied in different departments and activities of healthcare organizations to improve safety of patients and ensure the continuous improvement of the care systems.

Our final purpose is the contribution in improving the knowledge and the deployment of safety and security practices by using a rational approach in the hospital and its environment in Kingdom of Morocco and in the whole world. Toward achieving this goal, the first step is to produce a stat of art about the situation of the risk management topic in this country. Thus, the present paper aims to provide an overview about scientific and academic works that have interested in risk management and risk assessment developed or implemented in Moroccan healthcare sector specifically in hospitals and their stakeholders in order to establish a state of art and build a general knowledge about the maturity level of risk management culture in this country.

For this reason, this paper explains the method used to realize this study, then presents and discusses the work out results, after that, this paper highlights challenges and general parameters of selecting adapted risk assessment methods and techniques, and finally, it ends with some conclusions and perspectives.

2. Method 
The purpose of the present study is to assess the level of the risk management culture in Moroccan healthcare sector. To achieve this objective, we explore related works, and then we present and discuss results achieved. Therefore, we propose to follow the next steps:

- Collection and filter of data;

- Description of data;

- Discussion of results.

\subsection{Collection and Filter of Data}

In order to collect data related to our study, it is necessary to start with defining the space-time framework. In fact, the space-times framework is identified by all healthcare activities in Morocco (space), and works that have less than 5 years (time), from January,1st 2015 to the first trimester of 2020 (March, 31th 2020).

Associated data are collected from scientific web search engines like Google Scholar, ScienceDirect, Scopus and other databases. In order to reduce the risk of missing any associated article, we use a method for research based on set of terms.

In fact, the sentence used as a title for a research is subdivided into 3 parts of terms. The first part is related to the type of 'Risk Management' context, the second part concerns 'Healthcare' sector, and the third part concerns terms associated to the country of 'Morocco' (Table 1).

Table 1. Repartition of Terms used for search

\begin{tabular}{lll}
\hline & \multicolumn{1}{c}{ SENTENCE } & \\
\hline PART 1 & PART 2 & PART 3 \\
- Risk management & & \\
- Risk assessment & - Hospital & \\
- Safety patient & - Healthcare organizations & - Morocco \\
- Medical risk & - Healthcare system & \\
- Failure modes & - Health care & \\
- Adverse events & & \\
\hline
\end{tabular}

Therefore, the sentence used for searching related articles and papers in the web search engine has the following form:

SENTENCE $=[$ Terms part 1] $+[$ Terms part 2] $+[$ Terms part 3]

Table 1 illustrates the structure of sentence and all terms used in this research (terms per part).

Examples of research sentences:

SENTENCE 1 = Risk management + hospital + Morocco

SENTENCE 2 = Safety patient + healthcare + Morocco

SENTENCE 3 = Failure modes + hospital + Morocco

$\cdots$

We have made all combinations in this research to ensure that we have explored all related papers. Moreover, the combinations of sentences are made in 2 languages: English and French because Morocco is a Francophone country.

The filter adopted to accept a paper is based on 2 criteria: keywords and objectives used in paper. In fact, keywords used in the selected paper should include at least one of the terms applied in part 1 column of Table 1 . Also, the paper selected should aim to implement a risk management plan or system, to propose a new risk assessment tool, or to evaluate risk associated to a healthcare activity. Nevertheless, all researches that aim to treat risks related to diseases have been eliminated from our selection.

\subsection{Description of Data}

The purpose of this step is finding out useful information enable to provide a general view of risk management in Moroccan healthcare sector.

Parameters used in the data treatment process are: 
- Number of articles in the last 5 years: we have taken the period from January, 1st 2015 to March, 31th 2020 to explore how much Moroccan researchers are interested in risk management topic;

- Application fields : activities and healthcare departments covered by scientific publications;

- Methods and techniques used: there are several methods and techniques adopted to manage and assess risks. There are 2 kinds of these methods: usual methods that are cited by the International Organization for Standardization (ISO 31000:2018), and other methods which are named in our paper special methods.

\subsection{Discussion of Results}

Discussion of results is based on SWOT analysis. This tool aims to assess the general position towards a structure or a system. In fact, this approach classifies available information into 2 categories: external and internal. Each category includes 2 aspects, positive and negative.

The external category includes Opportunities (positive aspects) and Threats (negative aspects). The internal category includes Strengths (positive aspects) and Weaknesses (negative aspects).

In our study, we have limited the analysis in the internal position of risk management culture in Morocco. Consequently, discussion of results is based on analysing Strengths and Weaknesses of risk management culture in healthcare organizations.

\section{Results}

Appendix illustrates all papers collected which treat risk management topic related to healthcare sector in Morocco. Namely, the table 3 presents a set of information about each paper which are the title of article, the date of publication, the application field and the writing language.

\subsection{Number of Articles}

From January, 1st 2015 to March, 31th 2020 (5 years and 3 months) we found 11 papers in scientific literature.

The following figure (Fig 1) illustrates number of published articles per year throughout the period explored. In fact, this figure shows that in 2015, there was any published article, but in 2016 and 20172 articles are published. In 2018 we note that was a decrease from 2 to 1 published article. Nevertheless, in 2019 we notice that the number has multiplied (4 articles), and 2020 is progressing approximately with the same cadence as 2019 (2 articles in the first trimester of 2020).

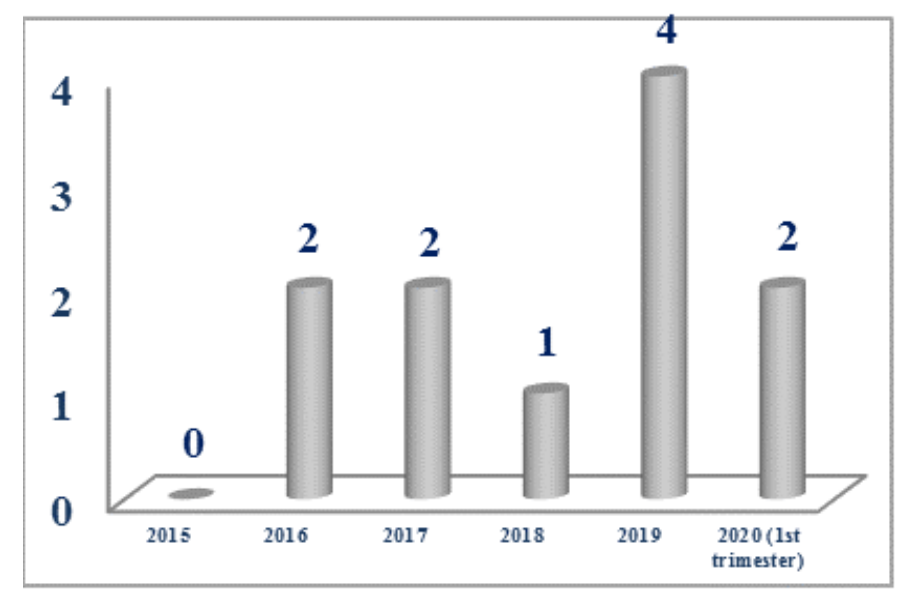

Fig. 1. Number of related articles per year

\subsection{Application Fields}

Healthcare context is a large sector which includes a diversity of services and activities. Many of these activities are exposed to high risks scenarios. For this reason, in this paragraph we explore the fields covered by researches and studies collected. 
In fact, we note in appendix that 9 departments and activities are covered by papers published namely: Medical device sterilization in hospital (2 articles); Hemovigilance activities (1 article); Hemodialysis (1 article); CT scan (1 article); Cytotoxic preparation (1 article); Hospital logistic and SCM (1 article); Medical supply chain (2 articles); Chemotherapy (1 article) and Healthcare outsourcing (1 article).

We notice that the present researches in the Appendix bellow have interested to the internal departments of hospital and the external activities of stakeholders.

Table 2 illustrates in which category belongs each activity or department.

Table 2. Categorization of healthcare activities

\begin{tabular}{ll}
\hline Hospital internal activities & External stakeholders activities \\
\hline - Medical device sterilization in hospital: 2 articles; & \\
- Hemovigilance activities: 1 article; & \\
- Hemodialysis: 1 article; & - Medical supply chain: 2 articles; \\
- CT scan: 1 article; & - Healthcare outsourcing: 1 article. \\
- Cytotoxic preparation: 1 article; & \\
- Chemotherapy: 1 article; & \\
- Hospital logistic and SCM: 1 article. & \\
\hline
\end{tabular}

Table 2 shows that around $73 \%$ of publications ( 8 articles) concerns internal activities of the hospital facing $27 \%$ (3 articles) that touch external activities of hospitals: majority of researches have focused on internal activities of healthcare organizations. Moreover, we notice in table 2 the fact of selected researches have covered only 6 departments and activities of hospitals.

\subsection{Methods and Techniques Used}

Table 3 categorizes techniques and methods used in risk management and risk assessment by each of the articles to make study or to implement the risk management plan or system.

Table 3. Database of researchers associated to risk management in Moroccan healthcare system in last 5 years all collected papers are indexed

\begin{tabular}{|c|c|c|c|c|}
\hline Title of article & Method/Technique used & $\begin{array}{c}\text { Date of } \\
\text { publication }\end{array}$ & $\begin{array}{l}\text { Application } \\
\text { fields }\end{array}$ & Language \\
\hline $\begin{array}{l}\text { Mapping of the risk management of sterilization of } \\
\text { medical devices excluding washing. Case of the } \\
\text { central sterilization of the IbnSina hospital Rabat }\end{array}$ & $\begin{array}{l}\text { Failure Mode, Effects \& Criticality } \\
\text { Analysis (FMECA) }\end{array}$ & $\begin{array}{l}\text { September } \\
2019\end{array}$ & $\begin{array}{l}\text { Medical device } \\
\text { sterilization in } \\
\text { hospital }\end{array}$ & French \\
\hline $\begin{array}{l}\text { Recipients adverse reactions in the IbnSina } \\
\text { Hospital of Rabat: State 1999-2013 }\end{array}$ & Special Method & $\begin{array}{l}\text { February } \\
2017\end{array}$ & $\begin{array}{l}\text { Hemovigilance } \\
\text { activities }\end{array}$ & French \\
\hline $\begin{array}{l}\text { Analysis of the infectious risk around the patient in } \\
\text { the hemodialysis unit of IbnSina Rabat hospital } \\
\text { using the failure modes, effects and criticality } \\
\text { analysis method }\end{array}$ & $\begin{array}{l}\text { Failure Mode, Effects \& Criticality } \\
\text { Analysis (FMECA) }\end{array}$ & March 2020 & Hemodialysis & French \\
\hline $\begin{array}{l}\text { Evaluation of radiation risks during CT brain } \\
\text { procedures for adults }\end{array}$ & $\begin{array}{l}\text { Special technique related to } \\
\text { radioprotection field }\end{array}$ & $\begin{array}{l}\text { September } \\
2019\end{array}$ & CT Scan & English \\
\hline $\begin{array}{l}\text { Mapping risk management in pre-disinfection of } \\
\text { medical devices in a hospital environment. The } \\
\text { example of the central sterilization laboratory of } \\
\text { the IbnSina Hospital, Rabat, Morocco }\end{array}$ & $\begin{array}{l}\text { Failure Mode, Effects \& Criticality } \\
\text { Analysis (FMECA) }\end{array}$ & $\begin{array}{l}\text { October- } \\
\text { December } \\
2018\end{array}$ & $\begin{array}{l}\text { Medical device } \\
\text { sterilization in } \\
\text { hospital }\end{array}$ & French \\
\hline $\begin{array}{l}\text { Incidents reported at the Cytotoxic Preparation } \\
\text { Unit of the National Institute of Oncology, Rabat, } \\
\text { Morocco }\end{array}$ & $\begin{array}{l}\text { Failure Mode, Effects \& Criticality } \\
\text { Analysis (FMECA) }\end{array}$ & $\begin{array}{l}\text { February } \\
2017\end{array}$ & $\begin{array}{l}\text { Cytotoxic } \\
\text { Preparation }\end{array}$ & English \\
\hline $\begin{array}{l}\text { LOGISTICS IN THE HOSPITAL: } \\
\text { METHODOLOGY FOR MEASURING } \\
\text { PERFORMANCE }\end{array}$ & $\begin{array}{l}\text { Special method: safety performance } \\
\text { indicators }\end{array}$ & March 2016 & $\begin{array}{l}\text { Hospital } \\
\text { logistic and } \\
\text { SCM }\end{array}$ & English \\
\hline $\begin{array}{l}\text { A prospective study on the analysis of risks } \\
\text { associated with medicines supply chain in Morocco }\end{array}$ & Special method & June 2016 & $\begin{array}{l}\text { Medical supply } \\
\text { chain }\end{array}$ & English \\
\hline $\begin{array}{l}\text { Risks related to the medical supply chain in public } \\
\text { hospitals in Morocco: Qualitative study }\end{array}$ & $\begin{array}{l}\text { Special method: Qualitative study to } \\
\text { classify the risks and errors which } \\
\text { negatively influence the availability } \\
\text { of pharmaceutical products }\end{array}$ & March 2019 & $\begin{array}{l}\text { Medical supply } \\
\text { chain }\end{array}$ & English \\
\hline $\begin{array}{l}\text { Chemotherapy supply chain safety: current data } \\
\text { from public oncology centers in Morocco }\end{array}$ & $\begin{array}{l}\text { Special method : descriptive data } \\
\text { analysis of failure modes }\end{array}$ & $\begin{array}{l}\text { July- } \\
\text { September } \\
2019\end{array}$ & Chemotherapy & English \\
\hline $\begin{array}{l}\text { A fuzzy multi-criteria decision analysis approach } \\
\text { for risk evaluation in healthcare logistics } \\
\text { outsourcing: Case of Morocco }\end{array}$ & $\begin{array}{l}\text { Multi-criteria decision } \\
\text { analysis (MCDA) }\end{array}$ & 2020 & $\begin{array}{l}\text { Healthcare } \\
\text { outsourcing }\end{array}$ & English \\
\hline
\end{tabular}


Therefore, according to the International Organization for Standardization (IEC/ISO 31010: 2019), there are about 30 methods and techniques used to manage and assess risks in different sectors. Nevertheless, there are other methods and techniques used for specific activities. In our study, we name any method which is not mentioned in ISO 31010, a Special method.

Thus, we present the repartition of the used method in the figure 2 (Fig. 2).

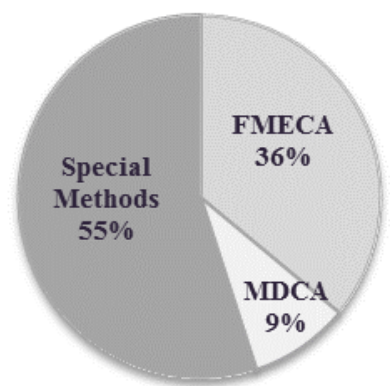

Fig. 2. Percentage of techniques/methods used in papers

We notice, according to the above figure (Fig.2) that Failure Mode, Effects \& Criticality Analysis (FMECA) approach is the most used method by Moroccan healthcare researchers (36\% of papers have used FMECA method), only 1 paper have used Multi-criteria Decision Analysis (MCDA) technique, and the rest, 6 other papers (55\%), each one of them have adopted a special method adapted to its application fields and its context.

\section{Choice of Techniques and Methods Used}

We have observed that the selected works have applied some methods such as FMECA method to implement their risk management systems. In fact, this method is widely used for not only in healthcare sector but in several sectors. But the question is: how can we guarantee that FMECA is sufficiently effective to assess, reduce and monitor high-level risks in a healthcare department or in a hospital?

The decision process of adoption of a method or a technique is not evident, because it depends on several parameters, such as characteristics of method: for example the strength of Hazard and Operability (HAZOP) method is strongly adopted in risk identification process for the reason that HAZOP uses guidewords to identify potential hazards and failures in systems. Nevertheless, simply identifying risks, without deep analysis, may have a negative impact on safety culture, leading to bad decisions and ultimately future risks (M. C. Emre Simsekler et al, 2019), in other side Fault Tree Analysis (FTA) shows its power in risk analysis process, because FTA method consists on searching causes and modelling interactions between scenarios basing on Boolean logic.

Moreover, the good knowledge of method by healthcare managers and professionals is a necessary parameter for the process of method adoption. In fact, methods and techniques used to assess risks have been generally developed in Safety-Critical industries like automotive sector, aviation sector and Gas \& Oil sector, and then they have been adapted to healthcare sector. Thus, this adaptation needs a deep knowledge of the method/technique within the objective of taking all advantages and establishing an efficient risk management system.

Furthermore, healthcare managers should heed the context for method adoption. In fact, nature of activity, processes interactivity, skills and competences of professionals and financial resources are indispensable parameters to decide which method or technique are the best to choose.

In the process of implementing and practicing risk management, healthcare decision-makers should choose the most adapted method and technique. This adoption is the output of a combination of different resources, conditions, challenges and objectives. Thus, there is no technique judged better than other, each technique and method has its own specificities. We can also adopt combination of a set of methods or techniques to get a hybrid method, but this combination needs a rational development in purpose to establish an efficient risk management system.

\section{Discussion}

We recalled that this study aims to provide a literature review of risk management systems in Moroccan healthcare sector. We started by collecting and describing data following by results analysis. This, paragraph 
aims to discuss strengths and weaknesses by, implicitly, providing recommendations of risk management culture in Moroccan healthcare system in order to contribute by a work than can support healthcare professionals, researchers and academics to improve the level of maturity of risk management culture in Kingdom of Morocco:

\section{Strengths}

- In general, researchers are interested, increasingly, by the topic of risk management and risk assessment in hospitals;

- Studies and researches have covered different fields in the healthcare system;

- There is a large use of efficient methods and techniques (FMECA for example have shown its efficiency in automotive and healthcare and other sectors).

\section{Weaknesses}

- Researches still not enough to establish a real risk management culture in Moroccan healthcare sector;

- Many departments and activities that provide high risk scenarios are not covered such as Emergency departments, Diagnosis departments, etc.

- There is an inequitable of geographic distribution of researches: about half of papers are focused on University Hospital Centre Ibn Sina of Rabat departments as application fields and study cases;

- There is no contribution of artificial intelligence in internal departments of hospitals even if artificial intelligence techniques have shown a huge efficiency as a risk assessment tool in healthcare and other sectors;

- Excepting FMECA and MCDA, there is any application of risk assessment techniques and methods;

- Lack of any work aims to develop a general framework to establish an efficient risk management or risk assessment system in all hospitals system or in specific departments.

\section{Conclusion}

Risk management becomes a necessary device in healthcare practices in order to build a safe system and provide a high quality of care in a safe context. Nevertheless, according to our study, the large majority of hospitals and healthcare organizations in Kingdom of Morocco lack the culture of risk management. Therefore, in order to develop a generalized risk management system which has the ability to be applied a in all healthcare activities and to overcome weaknesses cited in the previous paragraph, Moroccan healthcare decision-makers should create a national framework that could cover all levels from the strategic level of hospital to the operational level. Moreover, we need a real contribution from all human resources categories (medical, nursing, engineers, administrative...), and this condition needs also a big plan of communication, formation and also a sense of responsibility since the factor of communication still considered the key to succeed all projects related to risk management.

On the scientific research side, the risk management in healthcare sector is a topic that needs development and improvement. In fact, this study has showed us the large need, as researchers, to think about focusing not only on the ways to implement risk assessment plans in different healthcare processes but also to develop new approaches able to provide performance safety and security systems in our healthcare organizations.

\section{References}

1. Linda T. Kohn, Janet M. Corrigan, Molla S. Donaldson, Institute of Medicine (US) Committee on Quality of Health Care in America.

2. Guo, L. (2015). Implementation of a risk management plan in a hospital operating room. International Journal of Nursing Sciences, 2(4), 348-354.

3. Aggarwal, A., Aeran, H., \& Rathee, M. (2019). Quality management in healthcare: The pivotal desideratum. Journal of oral biology and craniofacial research, 9(2), 180-182.

4. Li, M., Liu, Z., Li, X., \& Liu, Y. (2019). Dynamic risk assessment in healthcare based on Bayesian approach. Reliability Engineering \& System Safety, 189, 327-334.

5. ISO 31000: 2018 Risk management-Guidelines.

6. IEC/ISO 31010:2019 Risk management - Risk assessment techniques.

7. Simsekler, M.E., Gurses, A.P., Smith, B.E., \& Ozonoff, A. (2019). Integration of multiple methods in identifying patient safety risks. Safety Science, 118, 530-537. 
8. Khomsi, Z., El Marnissi, S., El Harti, J., \& Allou, K.R.S. (2019). Mapping of the risk management of sterilization of medical devices excluding washing: Case of the central sterilization of the Ibn Sina hospital Rabat. The Hospital Pharmacist and Clinician, 549(3), 241-249.

9. Ouadghiri, S., Brick, C., Benseffaj, N., Atouf, O., \& Essakalli, M. (2016). Recipients adverse reactions in the Ibn Sina Hospital of Rabat: State 1999-2013. Clinical and Biological Transfusion, the official journal of the French Society of Blood Transfusion, 24(1), 23-27.

10. El Marnissi, S., Khomsi, Z., El Harti, J., Taoufik, J., Chaibi, A., Benamar, L., \& Bayahia, R. (2020). Analysis of the infectious risk around the patient in the hemodialysis unit of Ibn Sina Rabat hospital using the failure modes, effects and criticality analysis method. Nephrologie \& therapeutique, 16(2), 105-117.

11. Semghouli, S., Amaoui, B., El Kharras, A., Bouykhlaf, K., Hakam, O.K., \& Choukri, A. (2019). Evaluation of radiation risks during CT brain procedures for adults. Perspectives in Science, 12, 100407.

12. Allou, K.R.S., \& ElHarti, J. (2018). Mapping risk management in pre-disinfection of medical devices in a hospital environment: The example of the central sterilization laboratory of the Ibn Sina Hospital, Rabat, Morocco. The Hospital Pharmacist and Clinician, 53(40, 279-287.

13. Ouggague, K., Attjioui, H., Aliat, Z., Bouatia, M., \& Meddah, B. (2017). Incidents reported at the Cytotoxic Preparation Unit of the National Institute of Oncology, Rabat, Morocco. European Journal of Cancer, 72, S133.

14. Serrou, D., \& Abouabdellah, A. (2016). Logistics in the hospital: Methodology for measuring performance. ARPN journal of engineering and applied sciences, 11(5), 2950-2956.

15. Benazzouz, T., Echchatbi, A., \& Charkaoui, A. (2016). A prospective study on the analysis of risks associated with medicines supply chain in Morocco. In 6th International Conference on Information Systems, Logistics and Supply Chain, ILS Conference, 1-4.

16. Benazzouz, T., Charkaoui, A., \& Echchatbi, A. (2019). Risks related to the medical supply chain in public hospitals in Morocco: Qualitative study. The Hospital Pharmacist and Clinician, 54(1), 19-29.

17. Ouasrhir, A., Rahhali, R., \& Boukhatem, N. (2019). Chemotherapy supply chain safety: current data from public oncology centers in Morocco. European Journal of Oncology Pharmacy, 2(3), e14.

18. Mokrini, A.E., \& Aouam, T. (2020). A fuzzy multi-criteria decision analysis approach for risk evaluation in healthcare logistics outsourcing: Case of Morocco. Health services management research, 33(3), 143-155. 